\title{
Enhancing Student Learning By Narrowing The Gap Between Feedback Giving And Feedback Receiving
}

\author{
Eileen Goold Dr \\ Technological University Dublin, Ireland, eileen.goold@ittdublin.ie
}

Follow this and additional works at: https://arrow.tudublin.ie/ittengcon

Part of the Education Commons, and the Engineering Commons

\section{Recommended Citation}

Goold, E. (2016). Enhancing Student Learning By Narrowing The Gap Between Feedback Giving And Feedback Receiving. 3rd Teaching \& Education Conference, 3rd Teaching \& Education Conference, Barcelona, 28th June 2016. doi:10.20472/TEC.2016.003.010

This Conference Paper is brought to you for free and open access by the School of Engineering at ARROW@TU Dublin. It has been accepted for inclusion in Conference Papers by an authorized administrator of ARROW@TU Dublin. For more information, please contact arrow.admin@tudublin.ie, aisling.coyne@tudublin.ie, gerard.connolly@tudublin.ie.

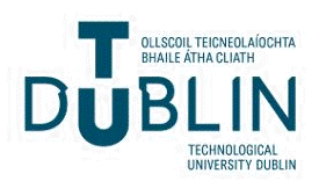


DOI: 10.20472/TEC.2016.003.010

\title{
EILEEN GOOLD
}

Institute of Technology Tallaght Dublin, Ireland

\section{ENHANCING STUDENT LEARNING BY NARROWING THE GAP BETWEEN FEEDBACK GIVING AND FEEDBACK RECEIVING}

\begin{abstract}
:
Feedback is one of the most powerful influences on learning and achievement. However the mere provision of feedback to students does not necessarily lead to improved learning. Feedback is ineffective if it does not close the gap between learning goals and students' performance. Often students do not have clear goals and they do not know what learning activities will improve their learning performance. Consequently the opportunity to learn from the feedback is lost.

Learning is a social process and while young people have increasingly strong social needs they struggle with academic language. This study investigates the influence of lecturers' feedback on students' learning and whether first year electronic engineering students at the Institute of Technology Tallaght Dublin (ITTD) benefit from a peer evaluation environment where students are enabled to detect and communicate quality criteria for specific coursework. A qualitative approach is used to capture students' views.

The results show that the opportunity to learn from lecturer feedback is not fully utilised. Instead learning is best achieved interactively and in a non-threatening environment. Students willingly engage in both giving and receiving feedback and clarifying misunderstandings and they show improved motivation. Engagement in a guided peer feedback environment additionally improves self-regulation, critical thinking skills and communications.
\end{abstract}

\section{Keywords:}

Feedback, Assessment, Communications, Language, Self-Regulated Learning

JEL Classification: 121,129 


\section{Introduction}

Feedback and formative assessment are key influencers of student learning. While there is no underestimating the value of assessment for learning compared to assessment of learning, the relationship between assessment and learning is complex. There is a view that assessment is a socially constructed concept. However students are excluded from discussions about assessment standards due to "markers' unarticulated tacit knowledge" about what students perceive as the "hidden curriculum". There is therefore a "need to create an open assessment dialogue"(Cartney, 2010).

\section{Learning in a social context}

Modern engineers work in teams and they communicate with other engineers around the world. However there is a view that communications and team work contribute significantly to the gap between engineering education and engineering practice (Tang and Trevelyan, 2009). The same may be true for doctors, economists and other professions.

"An introduction to the language of academia" and "the development of an inquirybased approach to learning" present new challenges for students transitioning into university (Wood and Solomonides, 2008). Changes affecting the transition to tertiary mathematics include: changes in teaching and learning styles, type of mathematics taught, levels of understanding, use of abstract concepts, use of formal mathematical language, exposure to numerous didactical differences in approaches to teaching, adjustment of personal learning strategies, more independent studying and exposure to new class groups and cultures (Clark and Lovric, 2008). A study of practising engineers found that, for many engineers, mathematics was much more challenging at university compared to school. Some engineers attribute the difficulty of engineering mathematics to the style of lecturing whereby university "lecturers don't teach, they lecture ...they tell you where the information is" and you "are very much left working it out for yourself". One engineer missed the "banter" of "the peer group that studied together" in school and he says that in college "the social element of the maths was gone". Another engineer learned mathematics in university by "a lot of us putting our heads together trying to get solutions" (Goold and Devitt, 2012).

The importance of positive social interactions in classrooms is well established (Ingram, 2008). Learning is fundamentally a social process; Vygotsky's theory of social constructivism is based on the idea that social interaction with others provides the foundation for individuals coming to understand ideas for themselves. Higher mental functions are socially formed and culturally transmitted and language is the means by which "reflection and elaboration of experience take place" and learning is a "highly personal" and also a "profoundly social process" (Vygotsky, 1978). 
Learning is best achieved interactively rather than through a one-way transmission process. Benefits of peer learning include improved understanding of course material, communication and teamwork skills (Haller et al., 2000). Students are more willing to learn in a safe and non-threatening environment from their peers compared to more hostile environments. Peer learning benefits both the learners and the tutors; peer tutors clarify their thoughts through explaining the subject matter to other students and all students learn to analyse problems from multiple perspectives thus also developing skills required in workplace situations (Zou et al., 2012). The dialogic feedback in peer learning situations where one student assumes the role of teacher facilitates group learning; students can determine whether explanations are effective and they have ability to query the "teacher" at the exact point of misunderstanding. The shared thinking element of student discussions is also good preparation for engineering practice, for example complex problems require input from many individuals and the optimal solution may differ from the unequivocally right answer (Haller et al., 2000). Cooperative learning is viewed positively by both men and women but more so by women. Women in engineering report negative experiences due to traditional instructional mode of individual work and competitive grading; they prefer and are more successful in collaborative learning environments. Men benefit from explaining course material to others while women mostly benefit from having the material explained to them (Felder et al., 1995).

\section{Value of feedback and formative assessment}

Feedback is defined as "information with which a learner can confirm, add to, overwrite, tune, or restructure information in memory, whether that information is domain knowledge, meta-cognitive knowledge, beliefs about self and tasks, or cognitive tactics and strategies" (Winnie and Butler, 1994). Feedback is only part of the teaching process; it happens after a student has responded to earlier instruction and it has little effect if the material studied is unfamiliar (Hattie and Timperley, 2007).

Feedback is one of the most powerful influences on learning and achievement (Hattie and Timperley, 2007) and it is a prime determiner of the processes that constitute selfregulated learning where students exhibit greater task engagement (Sadler, 2010). Self-regulated learning is a cyclical process whereby students set goals and plans, monitor progress and use feedback from prior experiences to adjust their current learning methods (Zimmerman, 2000). Students, who are motivated to attain a goal, engage in self-regulatory activities they believe will help them. Very often, the nature of schooling limits the degree of self-regulation and learning is regulated externally to the student. Social cognitive theory views self-regulation as comprising of three processes: self-observation (attention to aspects of one's behaviour), self-judgement (comparing current performance with one's goal) and self-reaction (behavioural, cognitive and affective responses to self-judgements). Anticipated consequences of behaviour enhance motivation and actual accomplishments enhance self-efficacy (Schunk et al., 2010). Self-regulated learners feel self-efficacious whereby self- 
efficacy beliefs influence goal setting and self-efficacious people set high goals and they also increase their efforts to maintain these goals (Zimmerman, 2000). Positive and negative mastery experiences (interpretation of past performances) were found to be the most prominent source of self-efficacy over the course of a freshman engineering mathematics course. Correcting students' previous misunderstandings and increasing student involvement in challenging learning environments impacted positively on students' self-efficacy (Brown and Burnham, 2012).

It is asserted that "feedback is capable of making a difference to learning, but the mere provision of feedback does not necessarily lead to improvement" (Sadler, 2010). Feedback often "misses the point"; the transmission model of feedback which is "largely about telling", feedback in the form of "knowledge of results" and feedback in the form of judgements and explanations are inadequate for complex learning (Sadler, 2013). Feedback at the personal level is rarely effective; praise is ineffective in enhancing learning (Hattie and Timperley, 2007) and negative feedback is counterproductive (Bandura, 1997). There is often a gulf between feedback giving and receiving (Hattie and Timperley, 2007). Feedback is ineffective if it is situated outside students' 'zone of proximal development' (Vygotsky, 1978) and consequently the opportunity to learn from the feedback lapses (Sadler, 2010).

The purpose of feedback is to close the gap between specific learning goals and students' actual performance (Sadler, 2010). Students are more likely to increase effort when the intended goal is clear and the expectancy for success is high (Kluger and DeNisi, 1996). Hattie and Timperley 2007 present that notions of "feed up", "feed back" and "feed forward": effective feedback must answer three questions asked by a teacher and/or by a student: "Where am I going? (What are the goals?), How am I going? (What progress is being made toward the goal?), and Where to next? (What activities need to be undertaken to make better progress?)". This model discriminates between four levels of feedback; the task (how well tasks are understood/performed), the processing (processes needed to understand/perform tasks), the regulatory (selfmonitoring, directing and regulating of actions) and the self (personal evaluations) levels. Feedback aimed to move students from task to processing and then from processing to regulation is most effective. Feedback about the task is powerful when it is about faulty interpretation and not lack of information. Further instruction is more powerful for students who lack necessary knowledge. Feedback at the process level includes processes and understandings necessary to learn the task. Feedback at the self-regulation level includes skill in self-evaluation and confidence to engage in more challenging tasks. Feedback about the self is least effective as it is usually unrelated to performance of the task. Students who develop effective error detection skills engage in self-feedback and seek better strategies to complete tasks or use their selfregulatory proficiencies (Hattie and Timperley, 2007).

Although feedback is among the major influences on learning and achievement, the type of feedback and the way it is delivered can be differentially effective. Learning 
from being told is flawed and criteria-standards templates prioritise specific criteria rather than quality in the global sense. Similarly without "purposeful peer assessment as a pedagogical strategy" incorporating task compliance, quality and criteria, key assessment concepts are invisible (Sadler, 2010). Sadler maintains that the task of teachers is not to coach students through complex tasks by offering ongoing judgements and advice; instead it is to teach students how to judge quality and modify their own work during production (Sadler, 2013). Similarly a proposed solution presented in this paper is "purposeful peer assessment" whereby students are enabled to judge the quality of their work (Sadler, 2010) and to develop a vocabulary for communicating quality (Sadler, 2013). Given that the construction of feedback is a valuable form of active learning (Nicol, 2011) and that peer learning can enhance students' third level education (Goold, 2014), this study investigates if peer feedback production has the potential to significantly enhance students' learning.

\section{Methodology}

The main objectives of this study are to investigate the influence of lecturers' feedback on students' learning and to establish if first year electronic engineering students at the Institute of Technology Tallaght Dublin (ITTD) would benefit from a peer evaluation environment. In the context of this study peer feedback refers to a peer evaluation environment. This is a learning environment where students collaboratively and with the lecturer's guidance learn to identify the type of response stipulated in a particular task, to detect quality criteria and to communicate the quality of specific coursework.

First year electronic engineering at ITTD comprise National Framework of Qualifications (NFQ) levels 6, 7 and 8 and in the first semester (14 weeks) students take six subjects: Mathematics, Electrical Circuits, Engineering Science, Computer Programming, Workshop and Learning to Learn. The study is incorporated into the Learning to Learn module which, in addition to equipping students with learning skills, also incorporates the implementation and communication of a group project. Students are encouraged to reflect on their learning and individual students' views of their learning, communicated in either learning journals or other formats, are confidential.

In order to ensure full participation this study was integrated into the assessment of the Learning to Learn module and was compulsory. There are three peer feedback parts:

I. Students are introduced to the concept of group discussion about quality criteria by displaying their Learning to Learn assignments, anonymously and with students' permission, to the whole class and openly discussing the quality of individual assignments.

II. Students' engagement in peer feedback for two modules involves students giving feedback to students and receiving feedback from other students with lecturer 
scaffolding. Students, equipped with quality criteria required for mid-semester examinations in two modules, are required to engage in giving and receiving feedback at levels of task, process, regulatory and self.

III. Students' peer review of previous students' Learning to Learn project reports involves students, with the lecturer's guidance, devising and implementing marking schemes with feedback for anonymous project reports.

This study is a comparison of students' learning experiences before and after engaging in peer feedback. A qualitative approach is used to capture and summarise students' views about their learning. As the class size is small (18 students) questionnaires, with both closed and open-ended questions, are used to collect the following data:

I. Students' level of peer engagement, students' ability to judge quality in their work and the impact of lecturers' feedback on students' learning

II. Students' subsequent views of whole class appraisal whereby students, together with the lecturer, collectively review each other's Learning to Learn assignments (student names are deleted) (week 7)

III. Students' learning from mid-semester examinations (week 10)

IV. Students' views about engaging in peer feedback for two modules (week 11)

V. Students' peer review of anonymous Learning to Learn project reports (week 12)

Both lecturer's feedback and peer feedback are studied in the context of the objective of feedback as defined in Table 1 and in the context of feedback levels as illustrated in Table 2.

\section{Table 1 Feedback Objective}

"Feedback needs to provide information specifically relating to the task or process of learning that fills a gap between what is understood and what is aimed to be understood".

Source: (Sadler, 1989)

Table 2 Feedback Levels

\begin{tabular}{|l|l|}
\hline Feedback Level & \multicolumn{1}{|c|}{ Description } \\
\hline Task & $\begin{array}{l}\text { Verify whether something is correct/ incorrect or how well } \\
\text { something is done }\end{array}$ \\
\hline Process & $\begin{array}{l}\text { Learning processes requiring understanding or completing the } \\
\text { task }\end{array}$ \\
\hline Self-regulation & Self-evaluation or confidence to engage further on a task \\
\hline Self & Personal e.g. "you are a great student" or "well done" \\
\hline
\end{tabular}

Source: (Hattie and Timperley, 2007) 


\section{Findings}

\subsection{Prior to Peer Feedback}

5.1.1 Finding 1 Peer discussion is limited to continuous assessment (CA) details

There is evidence that students engage with each other and in particular there is "ongoing discussion in the group around upcoming/outstanding work". Most engagement is about "CA dates" and "what's needed for CA". One student who lacks "confidence" states that there are "two main people I ask for help; one is in a similar position as me and I can relate with him especially in maths".

5.1.2 Finding 2 Lecturer feedback is sparse and mostly at task and personal levels

Students are mostly negative about the amount of feedback they receive from lecturers; "feedback is very brief if at all". While "lecturers are easy to talk to", students "hardly ever receive feedback" or "only get feedback for CAs". One student states "feedback is given in response to a question". Furthermore "some lecturers are quick others take ages".

Feedback is mostly at the task level where "students are shown their work after correction; this includes errors made and some suggestions how the work can be improved". There is little evidence of feedback at the process or self-regulatory levels; "only two lecturers will help you understand your mistakes or what is good about your work and how important it is". There is also personal feedback such as "you did well in that, keep up the good work".

\subsubsection{Finding $3 \quad$ Students show difficulty judging and communicating work quality}

Most students have difficulty judging the quality of their work. For example: one student "cannot tell if how I explained it will make sense to someone else", another student states "I am completely unsure of what is required for some of the tasks" and a further student states "I can be unsure if what I have done is correct".

Students show language difficulties. For example "there is a lot of new language in engineering and I find it hard to remember it all", "some words or definitions are really hard to learn" and "I struggle because I previously attended Irish speaking school".

\subsection{Class appraisal of Learning to Learn assignments}

5.2.1 Finding 4 Peer assessment benefits outweigh slightly uncomfortable process 
One response is: "I was taken by surprise when the slides were presented, but on reflection I have in the past number of weeks sat with different people in lectures and discussed some of the problems I was having difficulty with and also some I found easier. The group we are in is quite small and I think we all know each other now so I will have less difficulty in my work being displayed in the future. It would probably be more useful if we as a group met more often and discussed our course and subjects/modules".

\subsubsection{Finding 5 Peer assessment is at process and self-regulatory levels}

Peer assessment shows evidence of feedback at the process and self-regulatory levels and students are introduced to the concepts of quality and judging quality. Students' responses show students reflecting on learning processes, understanding and quality, examples include:

"I think it was a good idea as it gave an insight as to what each student in the class was feeling about the summary sheets. I think everyone benefitted from this as it gave others in the class a different way of doing each summary sheet. It opened other ways in learning. I think this could be used in future classes as it shows how everybody is and whether you are behind in learning while remaining anonymous".

"This showed me that if I talked to other classmates about assignments it could help me see what I have to do and how others understood the assignment. My work being presented to the class didn't bother me".

"I found this peer reviewing to be very useful for me because I was able to stop and look back at what I was writing and to see how others are doing in CAs. When I stopped and looked at my CA I found that what I wrote was slightly different than what I was hoping to show. I found that looking at other students' work allows me to learn from their mistakes and errors".

\subsection{Learning from mid-semester examinations}

\subsubsection{Finding 6 There is little learning resulting from mid-semester examinations}

One students' learning from mid-semester examinations is illustrated in Table 3 below. While the student recognises the need for further work, there is no evidence of learning processes requiring understanding.

\section{Table 3 Example of student's learning from mid-semester}

- Module 1 - "CAs outstanding or insufficient"

- Module 2 - "Remember to write units in. More work on force/stress/strain required"

- Module 3 - "Mini disaster need to do much more work on everything! Made errors on every question"

- Module 4 - "Did really well, "just keep doing what you're doing"

- Module 5 - "Need to chase for feedback. Did well, need to practise long division and memorise more methods although I did well in the exam" 
- Module 6 - "Need to chase for feedback. Don't understand the feedback given after a very brief time with my report, none the wiser. Lecturer going away so, pass"

Source: Study data

\subsubsection{Finding $7 \quad$ Mid-semester examinations are largely summative}

When asked to list five things they learned from one mid-term examination, students, while recognising that they need to "read questions correctly", "remember formulae" and "learn how to read a flowchart", students overall demonstrated little new understanding or confidence to engage further in learning tasks. Students' recollection of lecturer feedback include: "we had a chat about my errors", "useful when given", "can't remember any", "I was advised how to answer the questions correctly in the future", "lecturer showed me what not to do" and "I have learned from the mistakes I made".

While the second module is described as students' "least favourite subject", students generally say they performed well in the mid-term examination. The "lecturer went through the questions" in class before students had received both their results (grades) and their corrected examination scripts. "Exam technique", "units", "getting symbols mixed up" and "reading questions carefully" comprise the main student learning from the mid-term examination. It is stated that this learning occurred "during the exam and from results" as there "was no feedback given". There is another recollection that the lecturer "wrote all the corrections on the board", and the student says "I saw where I went wrong and where others went wrong". While one student states "I do not know where I made the mistake" another student states "I know where I went wrong" and a further student states "I know two stupid things I did but not everything". Students state that a "class before the test on units, symbols and formulae", "practice past exam questions" and "asking questions in lectures not only to learn but to understand what I am being taught" is required to enable them to get an A grade / $100 \%$ in future Engineering Science examinations. This suggests that students lack the necessary knowledge and that further instruction would be more beneficial than student feedback.

\subsection{Students' peer review of mid-semester examinations}

\subsubsection{Finding 8 Students say it is easier to talk to peers than to the lecturer}

Compared to lecturer feedback, students prefer peer feedback as "students are on my level", "I don't get as angry when students give me feedback", "peer to peer is less scary" and "it was easier to talk to my peers than my lecturer". Students also recommend to "use simple English" and "keep language clear and understandable" when giving feedback. Students generally "understood the feedback" they received; "it was delivered in a clear way". 


\subsubsection{Finding $9 \quad$ Peer feedback is at task, process, self-regulatory and self-levels}

Feedback at process levels is evident when students state that "correct answers, clear and understandable answers, correct method, units and formulae" are required to get full marks. Suggestions on how to improve students' work include "develop answers more", "practice similar questions to become faster and not to forget units", "show working, more revision, practise questions and review materials" and "units, read the question, attempt all questions, show method if possible, write down formulae".

Delivering feedback influences students' own learning. Examples of feedback at selfregulatory levels include: "I need to that too", "I could take the feedback I gave of practising to become faster", "I realised that I don't show how I arrived at my solutions" and "I did not answer questions as I would have marked them". When questioned about the benefits of this type of feedback exercise, students say: "yes, you will be able to learn more", "yes when marking student's papers it makes me realise where I made mistakes myself", "it helped me realise my strengths and weaknesses", "yes I will work on my weaknesses", "I learned from others" and "strangely I feel a bit more confident".

Students appreciate positive comments from their peers, for example "positive comments from the student were great", "student was encouraging despite my poor attempt" and "I felt proud of my work knowing someone else appreciates it". When asked how they responded to negative comments, students say "I got angry but it was ok", "comments on answers I got wrong are designed to help me improve in future" and "they are not personal".

\subsection{Students' peer review of Learning to Learn project reports}

\subsubsection{Finding 10 Engaging in peer assessment benefits students' own learning}

Students were required to identify marking schemes and comment about their learning resulting from assessing other students' project reports; sample responses are illustrated in Table 4. Students are generally positive about the learning benefits of assessing other students' project reports.

Table 4 Students' Marking Categories and Comments about Assessing Student Reports

\begin{tabular}{|l|l|}
\hline \multicolumn{1}{|c|}{$\begin{array}{c}\text { Students' Marking } \\
\text { Categories }\end{array}$} & \multicolumn{1}{c|}{ Comments about learning } \\
\hline "Referencing/ Research "I learned many pitfalls associated with completing a \\
Methodology/ Analysis/ Idea \\
flow/ Writing quality/ Content// \\
Clarity/ Use of visual dat I I think that reviewing the work of others like \\
Communication"
\end{tabular}




\begin{tabular}{|c|c|}
\hline $\begin{array}{l}\text { "Grammar/ Clarity/ Message/ } \\
\text { Use of images/ Use of Tables/ } \\
\text { Structure" }\end{array}$ & $\begin{array}{l}\text { This is a good learning exercise as it gives you } \\
\text { ption to see good reports, average reports and po } \\
\text { eports" }\end{array}$ \\
\hline $\begin{array}{l}\text { Presentation/Understanding of } \\
\text { Topic/Relevance to Subject/ } \\
\text { Easy to Understand/ } \\
\text { Information/ Unique/ Interest } \\
\text { to Audience/ Referencing }\end{array}$ & $\begin{array}{l}\text { "I felt that reviewing these reports was an effective } \\
\text { learning strategy, as it provides insight into how a } \\
\text { report may be viewed or graded by a } \\
\text { lecturer/examiner. This method also helped me to } \\
\text { realise what aspects of report writing I need to focus } \\
\text { on and helped to realise how to effectively implement } \\
\text { these aspects in my own reports in future" }\end{array}$ \\
\hline $\begin{array}{l}\text { "Presentation/ } \\
\text { Communication/ } \quad \text { Clarity/ } \\
\text { Organisation/ Writing quality/ } \\
\text { Analysis/ } \\
\text { Evidence of Understanding/ } \\
\text { Idea flow" }\end{array}$ & $\begin{array}{l}\text { "I found this exercise to be very useful because I saw } \\
\text { similarity in the mistakes students make. I learnt a lot } \\
\text { of these mistakes that now I am aware of most of } \\
\text { them and will be able to not make the same } \\
\text { mistakes. I also realised the referencing can be } \\
\text { easily forgotten". }\end{array}$ \\
\hline $\begin{array}{l}\text { "Presentation/ Understanding } \\
\text { of Topic/ Relevance to } \\
\text { Subject/ Easy to understand/ } \\
\text { Information/ Effort/ Interest to } \\
\text { Audience/ Referencing" }\end{array}$ & $\begin{array}{l}\text { "Seeing the mistakes that other people made } \\
\text { highlights these areas to watch out for. Emphasis } \\
\text { needs to be placed on conveying information } \\
\text { accurately not expressing a personal opinion. The } \\
\text { importance of using referencing plan from the }\end{array}$ \\
\hline
\end{tabular}

\section{Concluding discussion}

The findings in this study highlight the challenges of student learning. In particular lecturer feedback is sparse and ineffective, learning from mid-semester examinations is largely summative and students have difficulty judging the quality of their work and communicating with lecturers. This study illustrates that a peer evaluation environment, with appropriate lecturer guidance, is more effective than lecturer only feedback. While lecturer feedback is mostly at the task level, peer assessment shows evidence of feedback at the process and self-regulatory levels as students reflect on their own learning and plan their future learning.

There is evidence that lecturers do not set clear goals as students engage with each other to determine "what's needed for CA". Students' motivation (goal-directed behaviour, (Bandura, 1997)) is therefore compromised. Students say it is easier to talk to peers than to the lecturer. This supports the hypothesis that any discomfort is removed from peer assessment if the feedback is formative (Walker, 2015).

There is strong evidence in this study that feedback giving is a major influence on students' own learning; this is consistent with the research literature whereby giving feedback engages critical thinking skills and students therefore gain more benefit from giving feedback than from receiving it (Walker, 2015). While students need support in order to generate and deliver quality feedback (Walker, 2015), subsequent student involvement in peer appraisal is a means for engaging students in active learning, 
critical thinking and metacognition (Heywood, 2016). Equipping students with the tools required to write a good report is passive learning and contrasts with the more active approach of students using the same tools to judge the quality of student reports where they get an "insight into how a report may be viewed or graded by a lecturer/examiner".

The advantage of peer feedback compared to lecturer only feedback is attributed to the qualitative nature of the feedback given and received (Walker, 2015). Instead of the one-way transmission system of awarding a mark or grade and presenting the correct answers, students have an opportunity to clarify understanding and discuss new learning strategies. There is also evidence that communication between students is "clear and understandable" as students are all on the same "level". Students' willingness to engage in a new type of learning is remarkable. There are definite emotional benefits; "I felt proud of my work knowing someone else appreciates it" and "strangely I feel a bit more confident". This is consistent with the view that assessment is an "exercise of power" and that peer feedback moves the loci of power away from the lecturer and closer to the students (Cartney, 2010).

The advantages of peer feedback contrast with reasons why students do not act on lecturers' feedback, these include: vagueness or lack of detail, students do not understand the language or criteria and low motivation and self-perception (Walker, 2015). It is also reported that students performed better at giving feedback to their peers rather than making use of the feedback they received. Factors affecting students' response to peer feedback include: "perceived adequacy of feedback" (fairness, usefulness and acceptability), "affect" (affect student emotionally) and willingness to improve (Walker, 2015). In this study students are accepting of peer feedback and positively disposed to receiving feedback from peers and they say they are willing to work on weaknesses highlighted by their peers.

It is concluded that while the opportunity to learn from lecturer feedback is not fully utilised, engagement in a guided peer feedback environment additionally improves self-regulation, critical thinking skills and communications. Peer feedback as a pedagogical tool, reduces the gap between feedback giving and receiving.

\section{Acknowledgements}

This study is supported in part by a Teaching and Learning Fellowship from the Institute of Technology Tallaght, Dublin. The author wishes to thank the students who participated in the study.

\section{References}

BANDURA, A. 1997. Self-Efficacy: The Exercise of Control, New York, W. H. Freeman and Company. 
BROWN, S. \& BURNHAM, J. 2012. Engineering Student's Mathematics Self-Efficacy Development in a Freshman Engineering Mathematics Course. International Journal of Engineering Education, 28, 113-129.

CARTNEY, P. 2010. Exploring the Use of Peer Assessment as a Vehicle for Closing the Gap between Feedback Given and Feedback Used. Assessment \& Evaluation in Higher Education, 35, 551 564.

CLARK, M. \& LOVRIC, M. 2008. Suggestion for a Theoretical Model for the Secondary-Tertiary Transition in Mathematics. Mathematics Education Research Journal, 20, 25-37.

FELDER, R. M., FELDER, G. N., MAUNEY, M., HAMRIN JR., C. E. \& DIETZ, E. J. 1995. A Longitudinal Study of Engineering Student Performance and Retention. III. Gender Differences in Student Performance and Attitudes Engineering Education, 84, 151-163.

GOOLD, E. 2014. Using the Student Voice to Enhance First Year Engineering Learning at the Institute of Technology Tallaght. National Forum for the Enhancement of Teaching and Learning in Higher Education Dublin.

GOOLD, E. \& DEVITT, F. 2012. Engineers and Mathematics: Engineers' Stories on Career Choice and Professional Practice, Saarbrücken, Germany, Lambert Academic Publishing.

HALLER, C. R., GALLAGHER, V. J., WELDON, T. L. \& FELDER, R. M. 2000. Dynamics of Peer Education in Cooperative Learning Workgroups. Engineering Education, 89, 285-293.

HATTIE, J. \& TIMPERLEY, H. 2007. The Power of Feedback. Review of Educational Research 77, 81112.

HEYWOOD, J. 2016. The Assessment of Learning in Engineering Education, Practice and Policy, New Jersey, John Wiley and Sons, Inc.

INGRAM, N. 2008. Who a Student Sits Near to in Maths: Tension between Social and Mathematical Identities In: GOOS, M., BROWN, R. \& MAKAR, K. (eds.) 31st Annual Conference of the Mathematics Education Research Group of Australasia. University of Otago, New Zealand MERGA Inc.

KLUGER, A. N. \& DENISI, A. 1996. The Effects of Feedback Interventions on Performance: Historical Review, a Meta-analysis, and a Preliminary Feedback Intervention Theory Psychological Bulletin, $119,254-284$.

NICOL, D. 2011. Developing Students' Ability to Construct Feedback. Glasgow: Quality Assurance Agency for Higher Education, Scotland

SADLER, D. R. 1989. Formative Assessment and the Design of Instructional Systems Instructional Science, 18, 119-144.

SADLER, D. R. 2010. Beyond Feedback: Developing Student Capability in Complex Appraisal. Assessment \& Evatuation in Higher Education, 35, 535-550.

SADLER, D. R. 2013. Opening up feedback: Teaching learners to See. In: MERRY, S., PRICE, M., CARLESS, D. \& TARAS, M. (eds.) Reconceptualising Feedback in Higher Education: Developing Dialogue with Students. London: Routledge.

SCHUNK, D. H., PINTRICH, P. R. \& MEECE, J. L. 2010. Motivation in Education: Theory, Research, and Applications, Upper Saddle River, NJ, Pearson Educational International. 
TANG, S. \& TREVELYAN, J. 2009. Engineering Learning and Practice - a Brunei Practice? Australasian Association for Engineering Education Conference. Adelaide, Australia.

VYGOTSKY, L. S. 1978. Mind in Society: The Development of Higher Psychological Processes. In: COLE, M., JOHN-STEINER, V., SCRIBNER, S. \& SOUBERMAN, E. (eds.). Cambridge, MA Harvard University Press.

WALKER, M. 2015. The Quality of Written Peer Feedback on Undergraduates' Draft Answers to an Assignment, and the Use Made of Fedback. Assessment \& Evaluation in Higher Education, 40, 232-247.

WINNIE, P. \& BUTLER, D. 1994. Student Cognition in Learning from Teaching. In: HUSEN, T. \& POSTLEWAITE, T. (eds.) International Encyclopaedia of Education Oxford: Pergamon.

WOOD, L. \& SOLOMONIDES, I. 2008. Different Disciplines, Different Transitions. Mathematics Education Research Journal, 20, 117-134.

ZIMMERMAN, B. J. 2000. Attaining Self-Regulation: A Social cognitive Perspective In: BOEKAERTS, M., PINTRICH, P. R. \& ZEIDNER, M. (eds.) Handbook of Self-Regulation. San Diego, CA: Academic Press.

ZOU, T. X. P., KO, E. I. \& MICKLEBOROUGH, N. 2012. Promoting Multi-Layered Peer Learning in a Course on Engineering Grand Challenges. Social and Behavioral Sciences, 56, 74-87. 